\title{
ARTIGOS
}

\section{OS RESÍDUOS TÊXTEIS SÓLIDOS NO CONTEXTO DE ABORDAGENS SUSTENTÁVEIS: CICLO DE VIDA, ECONOMIA CIRCULAR E UPCYCLING}

SOLID TEXTILE WASTE IN THE CONTEXT OF SUSTAINABLE APPROACHES: LIFE CYCLE DESIGN, CIRCULARECONOMY AND UPCYCLING

\author{
ANA PAULA S. DE AVILA | UDESC \\ DULCE HOLANDA MACIEL, DRA. | UDESC \\ ICLÉIA SILVEIRA, DRA. | UDESC \\ SANDRA RECH, DRA. | UDESC
}

\section{RESUMO}

O objetivo dessa pesquisa é descrever atividades aplicadas no aproveitamento de resíduos têxteis que promovem a sustentabilidade. Abordam-se os conceitos: ciclo de vida, economia circular e upcycling, incluindo a reciclagem têxtil e a economia criativa nesses assuntos. Utilizou-se a pesquisa qualitativa e descritiva. Constatou-se que as práticas abordadas aliadas ao design contemplam a sustentabilidade.
\end{abstract}

PALAVRAS-CHAVE: Sustentabilidade; Ciclo de Vida; Economia circular; Upcycling

\begin{abstract}
The purpose of this research is to describe activities using solid textile waste that promotes sustainability. The approaches reported were life cycle design, circular economy and upcycling, including textile recycle and creative economy inside these main issues. Qualitative and descriptive research was the methodology adopted and the results show that the practices addressed allied to design contemplate sustainability.
\end{abstract}

KEYWORDS: Sustainability; Life Cycle Design; Circular Economy; Upcycling 


\section{INTRODUÇÃO}

No âmbito social e econômico questões relacionadas à sustentabilidade são amplamente discutidas e veiculadas nos meios de comunicação. O planeta e a biosfera estão sendo constantemente afetados de modo negativo pelo sistema rápido de extração-uso-descarte, o qual visa o consumo e o crescimento econômico em primeiro lugar. Desse modo, práticas sustentáveis e éticas estão começando a ser implementadas pelas organizações na fabricação de seus produtos e serviços, iniciando uma mudança de pensamento e conscientizando produtores e consumidores acerca do assunto, principalmente no que diz respeito à escassez dos recursos naturais indispensáveis à vida humana.

Uma das alternativas é a implementação de um processo produtivo que estuda todas as etapas do ciclo de vida do produto, pensando-o da melhor maneira possível durante toda sua concepção, existência e descarte. Outro conceito que vêm ganhando força no âmbito acadêmico e organizacional é o da economia circular, um novo modelo econômico que visa a regeneração dos recursos naturais e o impacto positivo dos bens de consumo que são fabricados a partir de então. Além dessas duas conceituações, existem também as práticas de upcycling, que fazem dos resíduos matéria-prima para novos produtos.

Nas empresas dos setores têxtil e de vestuário, um dos problemas que englobam essas práticas é a geração dos resíduos sólidos oriundos da confecção, onde muitas sobras e retalhos não possuem função alguma à não ser o descarte inadequado no meio ambiente. Nesse sentido, o objetivo dessa pesquisa é descrever atividades aplicadas no aproveitamento de resíduos têxteis, as quais promovem a sustentabilidade. Para tanto, aborda-se os conceitos já citados de ciclo de vida, de economia circular e de upcycling, incluindo-se questões sobre a reciclagem têxtil e a economia criativa. No que se refere à metodologia, do ponto de vista da abordagem do problema e seus objetivos esta é uma pesquisa qualitativa e descritiva, utilizando procedimentos técnicos bibliográficos para falar da temática proposta.

Inicialmente será apresentada uma breve explicação sobre o problema dos resíduos têxteis sólidos (tópico 2), para assim dar sequência às teorias ora apresentadas: em primeiro lugar, uma abordagem geral relacionando o ciclo de vida com a sustentabilidade (tópico 2.1), já que este último é o conceito que engloba toda a pesquisa; em um segundo momento, fala-se sobre o modelo de economia circular juntamente ao processo de reciclagem têxtil (tópico 2.2), mostrando exemplos de condutas nesta área e; por último, a prática do upcycling é atrelada à economia criativa (tópico 2.3), pelo fato de que juntas possibilitam uma única atividade, a qual promove sustentabilidade, inovação, inclusão social e diversidade cultural. Por fim, será apresentada uma discussão e considerações finais acerca do material elaborado.

\section{O PROBLEMA DA GERAÇÃO DOS RESÍDUOS TÊXTEIS SÓLIDOS}

Segundo relatórios da Fundação Ellen MacArthur (2017) nota-se que ainda vive-se em um modelo linear de consumo, onde matérias-primas virgens são vendidas, utilizadas e descartadas. Relacionando esse fato ao contexto específico dessa pesquisa, esse modelo resulta em toneladas de resíduos têxteis sólidos. A NBR 10.004/2004 (ABNT, 2004), que é a regulamentação no Brasil que comtempla a classificação dos resíduos sólidos quanto aos seus potenciais ao meio ambiente e a saúde pública, diz que os mesmos podem ser reutilizados se não forem contaminados nos processos fabris.

Desse modo, os retalhos e as sobras provenientes da confecção do vestuário/artefatos têxteis podem ser aproveitados para outro fim, o que prolonga o ciclo deste resíduo, que uma vez reusado se torna matéria-prima novamente, não permitindo seu descarte imediato na natureza. Trazendo a problemática para Santa Catarina, um estudo realizado por Correia et al (2016) nas indústrias do polo têxtil do Vale do Itajaí, no que diz respeito a confecção do vestuário de moda e aos resíduos têxteis sólidos, $59 \%$, dentre as 22 empresas da região de Blumenau analisadas, produzem até $2000 \mathrm{~kg}$ de retalhos têxteis por mês, sendo a maioria deles de fibra de algodão. Esse cenário pode se mostrar ainda mais alarmante quando observa-se que os outros $41 \%$ produzem além dessa quantidade, podendo gerar acima de $6000 \mathrm{~kg}$ de retalhos por mês (CORREIA et al., 2016).

O ponto preocupante dos dados apresentados está no fato de que se em uma escala regional, a quantidade de resíduos têxteis provenientes da confecção do vestuário já é enorme, imagina-se então em uma escala nacional ou mundial. A partir desta pesquisa (CORREIA et al., 2016), pode-se interpretar que este é um problema que precisa de políticas públicas mais eficientes, fiscalização constante e participação de toda sociedade. Dessa maneira, o presente trabalho buscou abordar o problema da geração dos resíduos têxteis sólidos juntamente às práticas que se relacionam com o conceito de sustentabilidade, onde a primeira abordagem a ser apresentada é o ciclo de vida do produto. 


\subsection{Ciclo de vida e sustentabilidade}

Promover um descarte adequado ou o reuso de resíduos de tecido dentro de uma empresa têxtil deve ser compreendido como uma tarefa empresarial para o equilíbrio correto do ecossistema e consequentemente, uma oportunidade de crescimento mercadológico. Essa proposta visa um menor impacto ambiental e um aproveitamento máximo de recursos dentro do próprio ciclo de vida, assim como uma conscientização acerca dos problemas ambientais e de consumismo. Como afirmam Fletcher e Grose (2011), é importante adotar uma visão abrangente do ciclo de produção e consumo do sistema da indústria da moda, pois todas as fases devem passar por melhorias para que uma sustentabilidade continuada possa ser alcançada.

Segundo Kazazian (2005) qualquer abordagem dentro de um ciclo deve ser pensada como um fluxo de melhora contínua, pois qualquer transformação de matéria-prima em produto vai gerar impactos ambientais. De acordo com Manzini e Vezolli (2008, p.100) "[...] o produto deve ser projetado considerando, em todas as suas fases, o conceito de ciclo de vida". Dessa maneira atribui-se que todas as atividades necessárias para produção, distribuição, utilização e descarte fazem parte de uma só unidade, tendo o designer então a tarefa de projetar todo o Life Cycle Design ( $L C D)$ :

Em outras palavras, a intenção é criar uma ideia sistêmica de produto, em que os inputs de materiais e de energia bem como o impacto de todas as emissões e refugos sejam reduzidos ao mínimo possível, seja em termos quantitativos ou qualitativos, ponderando assim a nocividade de seus efeitos (MANZINI; VEZOLLI, p.100, 2008).

Os autores afirmam que dentro do ciclo de vida considera-se desde a extração de recursos para a fabricação da matéria-prima integrante do produto até o último tratamento aplicado à esses mesmos materiais que o compuseram, ou seja do seu "nascimento" até a sua "morte" (MANZINI; VEZZOLI, 2008). Essa preocupação com sustentabilidade na fabricação de produtos é um assunto cada vez mais em pauta na indústria, principalmente na de vestuário, que é considerada uma das mais poluidoras do mundo.

Sobre esse assunto, Kazazian (2005) aborda que integrar o meio ambiente à estratégia de desenvolvimento da empresa é uma oportunidade e a torna interdependente, pois consegue-se reduzir custos através da implantação de tecnologias ou inovações a partir de uma visão de antecipação, gestão das consequências e compreensão das interações, o que envolve a redução das matérias-primas e dos volumes de resíduos em aterros, por exemplo.
Segundo o mesmo autor, essa abordagem foi apelidada de win-win (em português pode ser entendida com uma relação de "ganha-ganha"), por ser vencedora tanto para a empresa quanto para o meio ambiente (KAZAZIAN, 2005).

Tendo em vista esses conceitos, as aparas têxteis estão presentes em várias partes da confecção do produto dentro da fábrica, sendo elas refugos nas fases de corte, costura e acabamento. Portanto, antes de tudo, as mesmas devem ser minimizadas nesses processos, para que ao final desta fase do $L C D$ restem apenas sobras reais de tecido, ou seja, todo o processo de confecção do vestuário deve gerar o mínimo de retalhos nas operação de corte, costura ou acabamento determinadas. Essa abordagem pode ser entendida como uma estratégia para as empresas, consolidando as mesmas no mercado por muito mais tempo, uma vez que a busca de um projeto de design voltado à sustentabilidade pode associar práticas de inovação e inclusão social dentro de um negócio, fomentando uma moda mais ecoeficiente, próxima da economia criativa e de consumidores mais conscientes.

Dessa maneira, implantar estudos de $L C D$ dentro de empresas é uma necessidade, uma vez que as mesmas devem ser pensadas como um ecossistema e se apropriar da ideia de ciclo para uma economia de recursos naturais, inovar através de novas estratégias de gestão e se tornar industrialmente interdependentes, se aproximando de um modelo de produção autônomo (KAZAZIAN, 2009). Ouden (2012, tradução nossa) complementa que um ecossistema é uma estrutura resiliente hábil, que se adapta às mudanças do ambiente, que seus membros sofrem processo de co-evolução e também são interdependentes. Essa abordagem pode funcionar como um objetivo dentro do modelo de negócio de uma empresa têxtil, capaz de estimular um ecossistema mais regenerativo e restaurativo, palavras-chave da economia circular.

\subsection{Economia circular e reciclagem têxtil}

O conceito de economia circular é um novo modelo que, em seu último patamar, busca desvincular o consumo de recursos finitos à um desenvolvimento econômico global. Este, responde a desafios quanto à questão de recursos para empresas e países, os quais poderiam atribuir crescimento, maior quantidade de empregos e redução nos impactos ambientais (FUNDAÇÃO ELLEN MACARTHUR, 2017).

Segundo Laurindo (2016) a diferença do modelo atual, denominado de economia linear - o qual consiste em um esgotamento de recursos e devastação do meio ambiente devido à acelerada extração de recursos naturais, processamento em produtos ou matérias-primas, as quais são 
vendidas e após sua utilização são descartadas como resíduos - para um modelo econômico de economia circular é que, este último, torna o uso dos recursos mais racional e eficiente (Figura 01).
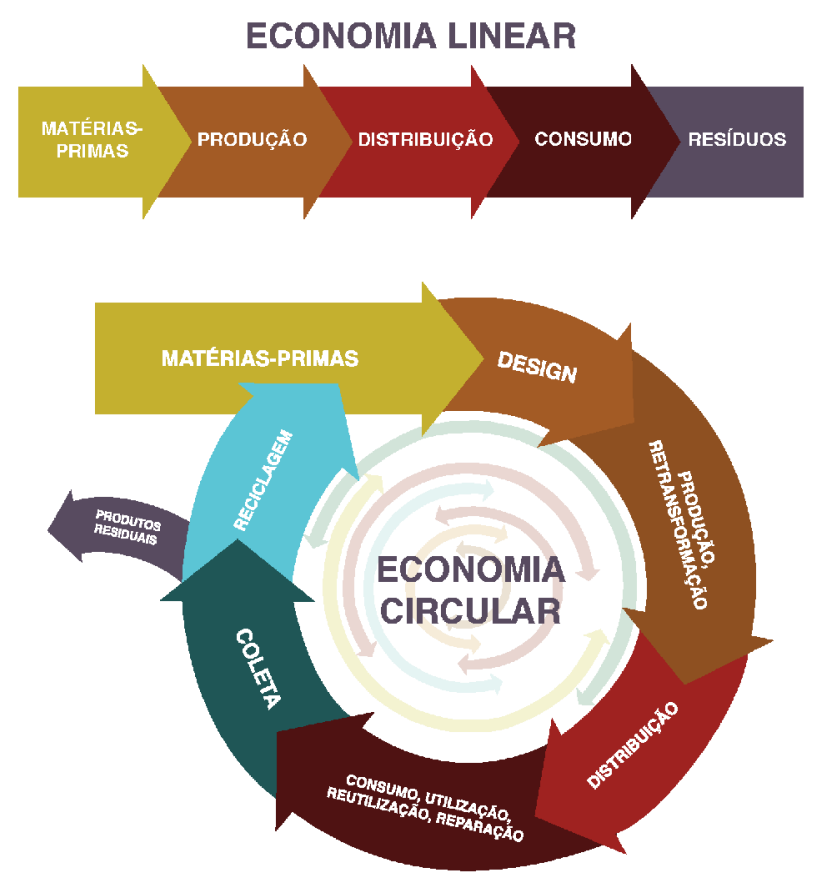

Figura 01 - Economia Linear e Economia Circular Fonte: Comissão Européia (2014, p. 2-3)

A autora ainda complementa que se os produtos ou peças fossem pensados desde sua fase de concepção de maneira que retornassem para seu ciclo natural, o consumo desenfreado não seria mais um problema (LAURINDO, 2016). Dessa forma, a Comissão Europeia (2014, p.1) aborda que

A transição para uma economia circular redireciona o foco para a reutilização, reparação, renovação e reciclagem dos materiais e produtos existentes. O que era visto como «resíduo» pode ser transformado num recurso.

Ainda sobre o modelo de economia linear, Braungart e McDonough (2013) afirmam que este pode ser denominado como "do berço à cova" ao contrário da economia circular, que possui a ideia de "berço à berço". O modelo linear foi pensado de uma forma que tudo a ser projetado será jogado fora quando não mais servir ou se acabar. Os autores argumentam "Mas onde é o "fora"? Certamente, o "fora" não existe de verdade" (BRAUNGART; MCDONOUGH, 2013, p.34). O mesmo foi concebido no século XIX quando os recursos naturais estavam presentes em abundância e o impacto ao meio ambiente não era uma preocupação generalizada, pois muitas pessoas acreditavam que a natureza era uma força subjugada e que teria a capacidade de se regenerar sempre e rapidamente (BRAUNGART; MCDONOUGH, 2013).

No contexto da economia circular, existem algumas ações relacionadas à geração de resíduos têxteis sólidos provenientes da confecção do vestuário, para que os mesmos voltem para a cadeia e sirvam de matéria-prima na confecção de novos produtos, sendo uma das principais alternativas a reciclagem têxtil. Segundo Zonatti (2015, p.85):

A reciclagem têxtil pode ser classificada dependendo das matérias- primas a serem reprocessadas, acarretando no uso de diferentes linhas de produção e processos específicos para obtenção dos produtos finais.

Quanto à essa classificação, Wang (2006, tradução nossa) afirma que a reciclagem têxtil mecanizada ou química, pode ser classificada como "aberta", pois os dois processos consistem em "abrir" o tecido para que ele retorne ao seu estado de fibra. A diferença é que o processo de reciclagem têxtil mecânica envolve cortar, desfiar, pentear e processar o tecido e, na reciclagem química são utilizados métodos enzimáticos, térmicos e entre outros processos químicos para que isto ocorra.

O processo de reciclagem química, relacionado à ideia de moda circular, já está presente, em maior ou menor grau, em alguns projetos de pesquisa e startups na Europa. Uma equipe de pesquisadores da Universidade de Aalto, na Finlândia, apoiados pelo projeto da União Europeia Trash-2-Cash e pelo governo finlandês, apresentou sua pesquisa em uma conferência da American Chemical Society em abril de 2017, relatando progressos em suas análises sobre reciclagem química de resíduos têxteis. Eles encontraram um novo líquido iônico capaz de dissolver o algodão em uma solução de celulose (para tecidos mistos de algodão e poliéster), sem afetar o poliéster e, a partir dessa solução, produzir fibras de celulose para fazer novos tecidos. Agora eles estão investigando se há a possibilidade do poliéster recuperado ser também reutilizado para produção de novas fibras (AMERICAN CHEMICAL SOCIETY, 2017, tradução nossa).

Outro exemplo é o Projeto Resyntex. Este é um projeto de pesquisa financiado pelo programa Horizon 2020 da União Europeia. Ele tem como objetivo criar um novo conceito de economia circular para as indústrias têxteis e químicas, utilizando simbiose industrial para produzir materiais virgens de segunda mão a partir de resíduos têxteis. Os objetivos principais desse projeto são (RESYNTEX, 2017, tradução nossa): 
- Projetar uma cadeia de valor completa para têxteis e químicos, desde a coleta do resíduo têxtil até a geração de novos suprimentos;

- Incentivar iniciativas coletivas e aumentar o envolvimento da população para uma consciência pública acerca do problema do lixo têxtil;

- Permitir a rastreabilidade dos resíduos usando um conjunto de dados. Os dados coletados avaliarão o desempenho da nova cadeia de valor por meio de uma avaliação do ciclo de vida e do custo do ciclo de vida;

- Desenvolver modelos de negócios inovadores para a indústria têxtil e química;

- Demonstrar uma linha completa de reprocessamento para componentes têxteis básicos, incluindo o tratamento de efluentes líquidos e sólidos.

Este projeto já conta com 20 parceiros espalhados por países da União Europeia, entre os quais estão associações industriais, empresas e institutos de pesquisa. O projeto conta com um pacote de atividades em 10 etapas, nos mais diversos níveis de análise da cadeia (RESYNTEX, 2017).

No Brasil, a tecelagem EcoSimple, localizada em São Paulo, já possui tecnologia para utilizar restos de resíduos têxteis na produção de novos fios, agregando também o uso de garrafas PET ao processo. O processo acontece em 2 fases principais: 1) Coleta de garrafas PET e sobras de tecido que são encaminhadas à pequenas cooperativas para separação por cor e tamanho; 2) De volta à empresa, os resíduos vão para as etapas de moagem e desmanche, limpeza e transformação em polímero e, por fim, fiação e tecelagem (BERLIM, 2016).

Os três exemplos apresentados mostram como o aproveitamento a partir da reciclagem de resíduos têxteis é possível e já está acontecendo. Essa alternativa encaixa-se em uma economia de moda circular e também repensa a utilização de tecidos reciclados como matéria-prima, implicando o uso de menos materiais virgens e mais insumos reciclados (FUNDAÇÃO ELLEN MACARTHUR, 2017). Segundo Fletcher e Grose (2011), mesmo fazendo um uso mais intensivo de recursos e energia, o processo de reciclagem é considerado ecológico, se comparado com a produção de fibra virgem.

De acordo com Berlim (2016), dentro das abordagens utilizadas para aproveitamento de resíduos têxteis existe, além da reciclagem, as práticas de reuso e upcycling. A autora compara as duas técnicas afirmado que a reciclagem se dá a partir da utilização de retalhos e sobras de tecidos para a fiação de novos fios e tecelagem e, já o reuso e o upcycling, criam ou utilizam essas aparas para a criação de novos produtos, o que demanda mais tempo e intensa atividade manual (BERLIM, 2016).

\subsection{Upcycling e economia criativa}

O upcycling é o aproveitamento de resíduos e têxteis descartados para a fabricação de novas peças. Segundo Berlim (2016, p.137), "o upcycling transforma produtos inúteis e descartáveis em novos materiais ou peças de maior valor, uso ou qualidade". Sobre este termo, Gwilt (2014, p.146) afirma que:

Upcycling é o termo usado para descrever uma técnica de se aprimorar e agregar valor a um produto ou material que, de outra forma, seria jogado fora. Diferente da reciclagem, que pode resultar em depreciação e redução do valor de um material ou produto, o upcycling permite que você aumente o aproveitamento e o valor de um material, prolongando sua vida. A técnica pode ser aplicada no design e na confecção de uma nova peça de roupa ou ser usada para reformar ou remanufaturar uma roupa já existente.

Ainda de acordo com Gwilt (2014), o upcycling permite agregar valor a uma roupa através de pequenas mudanças ou detalhes ou, até mesmo, a criação de peças inteiras de vestuário utilizando roupas usadas, sobras de tecido, retaIhos, aviamentos ou outros recursos que não possuiriam mais função. Por ser uma técnica de desconstrução, fazer upcycling demanda muito tempo e trabalho manual, o que acarreta em um aumento no custo final da peça acabada.

Como já citado, as matérias-primas para o upcycling de vestuário muitas das vezes são as roupas, tecidos ou aviamentos de descarte, o que também faz com que os recursos sejam finitos e únicos, gerando ao fim pequenas quantidades de produtos com muita exclusividade e valor afetivo. É pela conjuntura apresentada que o upcycling está diretamente ligado à economia criativa. $\mathrm{O}$ mesmo utiliza a criatividade para gerar algo novo ou dar um novo caráter a algo já existente, a partir de ideias que são pessoais, originais e significativas (HOWKINS, 2013), nesse caso, transformando de forma natural resíduos que seriam descartados em objetos com um valor econômico agregado.

A economia criativa, como atividade econômica, acontece quando a criatividade de um indivíduo ou de um grupo de pessoas produz produtos ou ideias comerciáveis, resultando em "[...] um produto criativo que eu defino como um bem ou serviço econômico resultante da criatividade e que tem um valor econômico" (HOWKINS, 2013, p. 13-14, grifo do autor).

O conceito de economia criativa foi definido pelo Ministério da Cultura em 2012 no Brasil, o qual tem seus fundamentos pautados a partir de quatro princípios: 
inclusão social, sustentabilidade, inovação e diversidade cultural (MINISTÉRIO DA CULTURA, 2012). Estes quatro fatores foram definidos de acordo com a realidade nacional: 1) A inclusão social é a base de uma economia cooperativa e solidária; 2) A sustentabilidade é um fator de desenvolvimento local e regional; 3) A inovação é a força motriz do desenvolvimento da cultura das expressões brasileiras e; 4) A diversidade cultural aborda a importância de uma economia na qual a base é a riqueza da diversidade cultural brasileira e a criatividade é processo e produto fruto dessa diversidade (MINISTÉRIO DA CULTURA, 2012).

Nesse sentido, no setor da moda e do vestuário brasileiros, já existem iniciativas unindo economia criativa e upcycling como alicerces para a criação produtos. Um exemplo é a marca brasileira MIG Jeans, que tem seus produtos criados a partir do upcycling de peças em desuso e resíduos têxteis, colocando de volta no mercado uma peça nova e exclusiva que estaria no fim da sua vida útil.

Fazendo uma análise de acordo com os dados disponíveis no site da MIG Jeans, a marca propõe a inclusão social através do trabalho de artesãs, as quais ficam livres para a criação de peças de acordo com seu fazer único. Já o fator inovação está presente na parceria com pequenas marcas e empreendedoras, buscando alavancar não somente o seu próprio mercado, mas também proporcionar uma oportunidade de negócio para outras pessoas. A sustentabilidade está presente no reuso de tecido para a concepção de novas peças de vestuário e no serviço de customização, onde o cliente também pode levar a sua peça para ser personalizada de acordo com seu gosto próprio, fomentando uma sustentabilidade social e ambiental. O pilar da diversidade cultural pode ser observado tanto no trabalho das artesãs brasileiras quanto na preferência por profissionais que residam no bairro em que a sede da marca se situa. Localizada no Vaz Lobo, Zona Norte do Rio de Janeiro, a MIG Jeans mostra em seu discurso o orgulho em representar minorias e dar oportunidades para as pessoas locais (MIG JEANS, 2017).

Nota-se que a aproximação entre a moda e a economia criativa é uma questão fundamental para o desenvolvimento de uma cultura pautada na sustentabilidade social, fomentando uma abordagem mais criativa, inovadora, colaborativa, circular e que valoriza o fazer manual.

\section{DISCUSSÃO}

As atuações voltadas para uma moda sustentável, ética e transparente estão ganhando força e sendo aplicadas, como visto nos conceitos e exemplos apresentados nesse artigo, porém nota-se ainda que são ações em desenvolvimento e se encontram em poucas práticas no cenário do modelo de consumo capitalista, principalmente no Brasil. Tanto a reciclagem quanto o upcycling são abordagens interessantes para o problema da geração de resíduos têxteis, visto quando são aplicados à um bom design e uma proposta de acordo com à ideia dos produtos da empresa/marca.

No entanto, nota-se que os tecidos e os outros materiais envolvidos no processo de fabricação do vestuário/artefato têxtil não são concebidos para os propósitos de reuso e reciclagem, o que é um problema dentro do ciclo de vida do produto e representa impactos negativos para toda cadeia, sociedade e atmosfera. Essa afirmação está pautada no sistema econômico linear e presente em quase todos os setores produtivos atuais: os recursos e matérias-primas não foram pensados em todas as fases da sua vida útil. Devido à isso, mais energia é gasta ao final da cadeia para estudos, pesquisas e novas possibilidades de reciclagem, quando o ideal era repensar o ciclo inteiro, desde a extração da matéria-prima na natureza até o descarte adequado.

Nesse sentido, as práticas de reuso e reciclagem devem ser vistas como uma alternativa de fim de ciclo e não como opção para somente amenizar os problemas ambientais e diminuir o uso de recursos na fonte, pois seria muito mais fácil reciclar, reusar e descartar um material ou produto que tenha sido pensado para este fim. É fato que a reciclagem e o reuso amenizam esses problemas e também geram renda para a economia criativa, porém não podem ser vistas como a salvação de um sistema baseado na concepção extração-uso-descarte. Por isso que a ideia da transição de uma economia linear para uma abordagem circular faz sentido.

Outro ponto importante para reflexão acerca do trabalho apresentado é que, dado ao estilo de vida acelerado da sociedade em que vimemos, o consumo rápido passou a fazer parte do dia-dia, o que já é considerado normal por muitas pessoas. A vida em sociedade requer participação e escolhas corretas para um bem-estar comum, por isso é importante que sejamos agentes sociais responsáveis pelo ecossistema e voltemos nossa consciência para que a questão de que a moda que consumimos também é uma opção política. Sob este ponto de vista, pode-se afirmar que o que foi apresentado nesse estudo ainda pode ser considerado uma "contra-corrente", pois a economia ainda sobrevive no contexto linear. Porém, a opção de consumir uma moda com valores que englobam a sustentabilidade, ou seja, tecidos reciclados ou reusados, propostas circulares, produção justa e local é uma escolha que já existe e contribui para a mudança. 


\section{CONSIDERAÇÕES FINAIS}

Como objetivo principal, esse estudo teve o propósito de abordar três macro conceitos ligados à sustentabilidade na moda no que diz respeito à geração dos resíduos têxteis sólidos: o ciclo de vida, a ideia de economia circular e o upcycling. Essa ideia inicial foi complementada com a reciclagem têxtil e com a economia criativa, duas práticas importantes envolvidas nesses conceitos. Tanto a reciclagem quanto o upcycling já são opções dentro de um sistema de economia circular que engloba o design, a produção, o consumo, o reuso, a reciclagem e o descarte, com a possibilidade de quase infinitos ciclos de consumo, reuso e reciclagem na cadeia, prolongando o tempo de vida útil de materiais e produtos no ecossistema.

Nesse sentido, nota-se que o projeto de design auxilia na construção de um novo tipo de consumo e consumidor na moda, os quais se importam com produtos e serviços que possuam critérios abrangendo os valores sustentáveis. Repensar os ciclos de vida é importante para o crescimento da oferta de produtos com o maior grau de sustentabilidade possível na moda e, o designer, possui capacidades competentes para esta tarefa, assim como a criação de novas iniciativas positivas dentro deste processo. Para futuros estudos, focar em mais iniciativas de design existentes que estejam em torno dessa abordagem e possuam propostas inovadoras seria uma maneira interessante de conceber um estado da arte em torno dessas práticas dentro da indústria têxtil e de moda.

\section{REFERÊNCIAS}

ABNT - ASSOCIAÇÃO BRASILEIRA DE NORMAS TÉCNICAS. NBR 10004 - Resíduos Sólidos Classificação. Rio de Janeiro: 2004. 77p.

AMERICAN CHEMICAL SOCIETY (Estados Unidos). Upcycling 'fast fashion' to reduce waste and pollution. 2017. Disponível em: <https://www.acs.org/content/acs/en/pressroom/newsreleases/2017/april/upcycling-fast-fashion-to-reduce-waste-and-pollution. html>. Acesso em: 30 set. 2017.

BERLIM, Lilyan. Moda e Sustentabilidade: Uma reflexão necessária. São Paulo: Estação das Letras e Cores, 2016. 2 reimpressão. $159 \mathrm{p}$.

BRAUNGART, Michael; MCDONOUGH, William. Cradle to Cradle: criar e reciclar ilimitadamente. São Paulo: Editora G. Gili, 2013. 192 p. Tradução de Frederico Bonaldo.
COMISSÃO EUROPÉIA, Directorate-General for Environment. A Economia Circular - Interligação, criação e conservação de valor. EU Law and Publications: 2014. Disponível em: <https://publications.europa. eu/en/publication-detail/-/publication/c8cfd1ae-6285-40ba-879f-f2e78e4c2b6e/language-pt $>$. Acesso em: 06 out. 2017.

CORREIA, Jeferson et al. Diagnóstico da Produção de Resíduos da Indústria da Confecção na Região de Blumenau. In: $4^{\circ}$ Congresso Científico Têxtil e Moda. Blumenau: 2016. Anais... Disponível em: <http:// www.contexmod.net.br/index.php/quarto/article/ view/426>. Acesso em: 25 set. 2017.

FLETCHER, Kate; GROSE, Lynda. Moda \& Sustentabilidade: Design para mudança. São Paulo: Editora Senac, 2011. 192 p. Tradução de Janaína Marcoantonio.

FUNDAÇÃO ELLEN MACARTHUR. Rumo à Economia Circular: $O$ racional de negócio para acelerar a transição. 2017. Disponível em: <https://www.ellenmacarthurfoundation.org/pt/publicacoes>. Acesso em: 12 out. 2017.

GWILT, Alison. Moda sustentável: um guia prático. São Paulo: Gustavo Gili, 2014. 176p. Tradução de Márcia Longarço.

HOWKINS, John. Economia Criativa: Como ganhar dinheiro com ideias criativas. São Paulo: M. Books do Brasil Editora Ltda, 2013. 271p. Tradução de Ariovaldo Griesi.

KAZAZIAN, Thierry (Org.). Haverá a idade das coisas leves: design e desenvolvimento sustentável. 2. ed. São Paulo: Editora Senac São Paulo, 2009. 194 p. Tradução de Eric Roland Rene Heneault.

LAURINDO, Michelly. A Viabilidade da Economia Circular à Luz da Política Nacional de Resíduos Sólidos: Lei 12.305 de 02 de agosto de 2010. 2016. $61 \mathrm{f}$. Trabalho de Conclusão de Curso (Graduação em Ciências Econômicas) - Departamento de Economia e Relações Internacionais, Universidade Federal de Santa Catarina, Florianópolis, 2016.

MACHADO, Poliana Gomes Silveira; LEONEL, Jordan Nassif. PRÁTICAS DE RECICLAGEM DE RESÍDUOS TÊXTEIS: UMA CONTRIBUIÇÃO PARA A GESTÃO 
AMBIENTAL NO BRASIL. Revista de Educação Superior do Senac-RS - Competência, Porto Alegre, v. 7, n. 1, p.129-145, jan. 2014. Semestral. Disponível em: <http://seer.senacrs.com.br/index.php/RC/article/ view/151>. Acesso em: 29 set. 2017.

MANZINI, Ezio; VEZZOLI, Carlo. O Desenvolvimento de Produtos Sustentáveis: Os requisitos ambientais dos produtos industriais. São Paulo: Edusp, 2008. 368 p. Tradução de Astrid de Carvalho.

MIG JEANS. Sobre nós. 2017. Disponível em: <https:// www.migjeans.com.br/sobre> . Acesso em: 12 out. 2017.

MINISTÉRIO DA CULTURA. Plano da Secretaria da Economia Criativa: políticas, diretrizes e ações. 2012. 156p. Disponível em: <http://www.cultura.gov.br/documents/10913/636523/PLANO+DA+SECRETARIA+D A+ECONOMIA+CRIATIVA/81dd57b6-e43b-43ec-93cf2a29be1dd071>. Acesso em: 12 out. 2017.

OUDEN, Elke Den. Innovation Design: Creating Value for People, Organizations and Society. Londres: Springer, 2012. 196 p.

RESYNTEX (Bélgica). The Project. 2017. Disponível em: $<$ http://www.resyntex.eu/the-project $>$. Acesso em: 30 set. 2017.

WANG, Youjiang (Ed.). Recycling in Textiles. Cambridge: Woodhead Publishing Ltd e CRC Press LLC em parceria com The Textile Institute England, 2006. 229 p.

ZONATTI, Welton Fernando. Geração de Resíduos Sólidos da Indústria Brasileira Têxtil e de Confecção: Materiais e processos para reuso e reciclagem. 2016. 251 f. Tese (Douturado em Sustentabilidade) - Escola de Artes, Ciências e Humanidades, Universidade de São Paulo, São Paulo, 2016.

\section{AUTORES}

ORCID: https://orcid.org/0000-0003-2845-4357.

ANA PAULA SANTOS DE AVILA | Universidade do Estado de Santa Catarina | Centro de Artes | Moda | Florianópolis, SC. Brasil | Correspondência para: Av. Madre Benvenuta, $n^{\circ}$ 1907, Itacorubi, Florianópolis/SC. CEP: 88.035-901 | E-mail: apsavila@gmail.com

ORCID: https://orcid.org/0000-0002-0602-0198

DULCE MARIA HOLANDA MACIEL, DRA. | Universidade do Estado de Santa Catarina | Centro de Artes | Moda | Florianópolis, SC. Brasil | Correspondência para: Av. Madre Benvenuta, no 1907, Itacorubi, Florianópolis/SC. CEP: 88.035-901 E-mail:dulceholanda@gmail.com

ICLÉIA SILVEIRA, DRA. | Universidade do Estado de Santa Catarina | Centro de Artes | Moda | Florianópolis, SC. Brasil | Correspondência para: Av. Madre Benvenuta, $n^{\circ}$ 1907, Itacorubi, Florianópolis/SC. CEP: 88.035-901 | E-mail: icleiasilveira@gmail.com

ORCID: https://orcid.org/0000-0002-0062-6914

SANDRA REGINA RECH, DRA. | Universidade do Estado de Santa Catarina | Centro de Artes | Moda | Florianópolis, SC. Brasil | Correspondência para: Av. Madre Benvenuta, $n^{\circ}$ 1907, Itacorubi, Florianópolis/SC. CEP: 88.035-901 | E-mail: sandra.rech@udesc.br

\section{COMO CITAR ESTE ARTIGO}

AVILA, Ana Paula Santos de; MACIEL, Dulce Maria Holanda; SILVEIRA, Icléia; RECH, Sandra Regina. Os Resíduos Têxteis Sólidos no Contexto de Abordagens Sustentáveis: Ciclo de Vida, Economia Circular e Upcycling. MIX Sustentável, [S.I.], v. 4, n. 3, p.1724, out-mar. 2018. ISSN 24473073. Disponível em: $<$ http://www.nexos.ufsc.br/index.php/mixsustentavel>. Acesso em: dia mês.ano. doi:https://doi. org/10.29183/2447-3073.MIX2018.v4.n3.17-24.

DATA DE ENVIO: 16/04/2018

DATA DE ACEITE: 01/08/2018 